\title{
Examining a domain-specific link between perceived control and conspiracy beliefs: a brief report in the context of COVID-19
}

\author{
Ana Stojanov ${ }^{1}$ (D) Jamin Halberstadt ${ }^{1} \cdot$ Jesse M. Bering ${ }^{2} \cdot$ Nikolina Kenig $^{3}$ \\ Accepted: 7 June 2021 / Published online: 15 June 2021 \\ (C) The Author(s), under exclusive licence to Springer Science+Business Media, LLC, part of Springer Nature 2021
}

\begin{abstract}
Although anecdotal evidence suggests that control-threatening situations are associated with an increase in conspiracy beliefs, existing research does not support this "compensatory control" hypothesis. In the current study, we test a more refined hypothesis: that the link between control threat and conspiracy beliefs is domain specific, such that perceived control in a particular domain should lead to conspiracy beliefs pertaining to that domain only. Moreover, given that conspiracy beliefs are stigmatized (i.e., not socially acceptable), we propose that they should be endorsed only when other compensatory systems are frustrated. We test these ideas in the context of the COVID-19 pandemic. Participants from North Macedonia and New Zealand, who differed in perceived government effectiveness, filled in a questionnaire measuring domain-specific and domain-general perceived control, as well as domain-specific and domain-general conspiracy beliefs. As expected, domain specificity of the control threat predicted domain-specific conspiracy beliefs in the Macedonian group only. The results have implication for compensatory control theory, suggesting that the compensatory process may not always be as fluid as believed.
\end{abstract}

Keywords Perceived control · Conspiracy beliefs · COVID-19 · Compensatory control · Conspiracy theories

COVID-19 was created in a Chinese lab. COVID-19 was released so that the pharmaceutical industry could profit financially from new medicine or a vaccine. COVID-19 is a covert scheme by several power sources aiming to establish a new world order. These statements are examples of conspiracy theories - implausible explanations for significant social or political events that postulate powerful agents working in secret to achieve a malevolent goal, and which usually are contrary to the official explanations offered by the relevant epistemic authorities (Stojanov \& Halberstadt, 2019).

According to the functionalist perspective (Boden et al., 2016; Cummins, 1975; Wright, 1973), beliefs often serve specific motivational needs. For example, belief in supernatural agents may stem, in part, from an innate drive to avoid death anxiety (Norenzayan \& Hansen, 2006), or belief that victims

Ana Stojanov

ana.stojanov@otago.ac.nz

1 Department of Psychology, University of Otago, William James Building, 275 Leith Walk, Dunedin 9016, New Zealand

2 Centre for Science Communication, University of Otago, Dunedin, New Zealand

3 Department of Psychology, Ss Cyril and Methodius University, Skopje, North Macedonia deserve what they get from the need to see the world as a just place (Lerner, 1980). Similarly, research on conspiracy theory beliefs has pointed to several such functions, linked to a suite of motives which Douglas et al. $(2017,2019)$ have broadly classified into three categories: epistemic, existential and social. In particular, the need to perceive the world as ordered and non-random, an existential motive, has been frequently linked to conspiracy theory beliefs (e.g., Kay et al., 2008; Laurin et al., 2008), but so far the causal evidence has been ambiguous or weak (Stojanov \& Halberstadt, 2020). In this paper, we test a more refined hypothesis, that control threats do encourage conspiracy theory beliefs, but only when the latter pertain to the threatened domain, and only when other means of restoring control are unavailable. We test these ideas in a field study, surveying participants from two countries that differ meaningfully in their views of the effectiveness of their governments.

\section{Compensatory Control Theory}

Perhaps the most clearly elucidated theory of control, compensatory control theory, assumes that having a sense of control satiates a higher-order need to perceive the world as structured and ordered (Kay \& Sullivan, 2013). If individuals 
believe that their experiences are the result of their own actions, they are more likely to interpret their environment as ordered and manageable. However, people do not always exert control, or perceive that they have it. How do people then manage to satisfy the need for a structured environment if their own causal role in it is unstable?

Compensatory control theory posits a cognitive substitutability between feelings of internal and external control. That is, when personal agency is left wanting, people nevertheless imbue the world with order and structure by relying on external systems. Believing that outside forces are responsible for events beyond the self's control enables the individual to satisfy their higher-order need for structure and non-randomness, by providing the sense that someone, at least, is in control.

Much research has confirmed the general hypotheses generated from compensatory control theory. For example, when personal control is experimentally threatened, participants are more likely to believe in a controlling God vs. a nonintervening "creator" God (Kay et al., 2008; Kay et al., 2010), to believe in precognition (Greenaway et al., 2013), to perceive patterns in noisy images (Whitson \& Galinsky, 2008), to show support for the government (Kay et al., 2008), and to prefer structured scientific theories (e.g., that moral development is staged rather than a continuum; Rutjens et al., 2013).

Although this theoretical framework has been applied to conspiracy theory beliefs as well (e.g. Kay et al., 2015; Kay $\&$ Eibach, 2013), it is unclear whether such beliefs are in fact an effective means of restoring perceived control. For example, people should favour benevolent and culturally accessible means for compensatory control (Kay et al., 2008; Kay \& Sullivan, 2013), but conspiracy beliefs, being stigmatized views postulating malevolent agents (Lantian et al., 2018), are neither. In addition, a recent meta-analysis examining the experimental effects of lack of control on conspiracy beliefs (Stojanov \& Halberstadt, 2020), offered no evidence for the expected effect.

Stojanov et al. (2020) argued, however, that conspiracy beliefs could be a suitable compensatory control mechanism, but only when other systems are unavailable or frustrated. In one study (Study 6), for example, the authors randomly assigned American participants to either a control threat or control affirmation group, with half of each group being further assigned to read either a (true) historical example of government competence or incompetence (the passages related to American responses to Hurricanes Irma and Katrina, respectively). The expectation was that only participants whose control was threatened and who were allocated to the incompetent government scenario would increase their endorsement of conspiracy theories. The results were in the predicted direction, though were not statistically significant.

However, it is worth revisiting this question in a "naturalistic" setting. There are some indications that the artificial tasks used to threaten control do not consistently have the desired effect (van Elk \& Lodder, 2018), and the effectiveness of the manipulation in Stojanov et al. (2020) was not assessed. Moreover, reading about a single incident in which a government acted incompetently may not be enough to shatter participants' underlying belief in government as means of order and control. By contrast, being an actual citizen of a society who experiences the recurring incompetence of their government should lead to views of its general untrustworthiness and ineffectiveness.

Government Effectiveness in Response to COVID-19 The COVID-19 pandemic was met with varying responses, of varying effectiveness in different countries. In particular, New Zealand and North Macedonia represent very different approaches and rates of success. Although both countries acted quickly and resolutely, New Zealand became world renowned for its effective communication, science-driven policy, and public compliance, while North Macedonia, despite implementing a series of ad-hoc measures, did not manage fight the virus effectively. For example, New Zealand ranks first out of 53 economies on Bloomberg's resiliency index (Chang et al., 2020), which is based on ten indicators such as one month cases per 100,000 , one month case fatality rate, total deaths per million etc. (Chang \& Hong, 2020). While North Macedonia does not feature on that list, a separate ranking for the countries from the Balkan region (Евросимоски, 2020) reveals that North Macedonia's statistics are among the worst in that region, while Greece's (a country ranked 31/53 on the Bloomberg list) are among the best, giving some indication about the performance of North Macedonia relative to New Zealand. Indeed, by the end of our data collection (May 12, 2020) North Macedonia had more than two and half times as many total cases per million, and more than ten times as many total deaths per million, as New Zealand (https:// ourworldindata.org/coronavirus-data). As of December 14, 2020, North Macedonia ranks fourth out of 150 countries in terms of death per million, while New Zealand ranks 135th.

Even before the emergence of the new coronavirus, New Zealand and North Macedonia differed in terms of their reputation for competence at home and abroad. Between 2014 and 2019, New Zealand ranked first or second out of 198 countries in terms of lack of corruption (Transparency International, n.d.). North Macedonia's rank on the same list has ranged from 64th to 107 th, further contributing to the perception that the government is not capable of dealing with crises effectively.

Given these different reputations and outcomes, we predicted, first, that New Zealanders would perceive their own government as more effective than Macedonians would view theirs. Second, based on the reasoning above, we hypothesized that perceived control would predict conspiracy theory beliefs only in the North Macedonian, but not in the New Zealand, sample. That is to say, since only the Macedonian 
Fig. 1 Search interest relative to the highest point on the chart for the given region (worldwide) and time. A value of 100 is the peak popularity for the term. A value of 50 means that the term is half as popular. A score of 0 means that there was not enough data for this term. (Source: Google Trends)

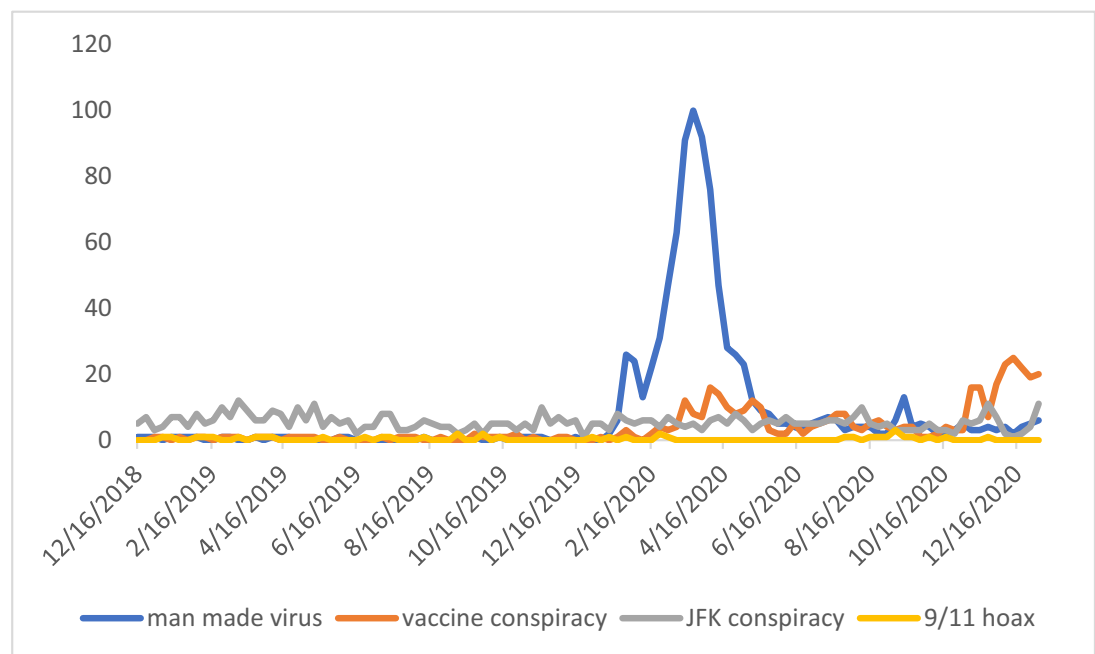

participants lacked a readily available compensatory control system (i.e., because the most salient source of order, central government, is viewed as incompetent), perceived lack of control should be compensated by belief in conspiracy theories.

\section{Generic Vs. Specific Conspiracy Beliefs}

Within the framework of compensatory control theory, the compensation process has been assumed to be fluid, or "domain-general," such that the nature of the control threat is not meaningfully linked to the type of compensation that will be effective. For example, if someone is feeling a threat to their personal control because of an economic crisis, the theory does not give precedence to the belief that the crisis was caused by the 'greedy bankers' over the belief in, say, vaccines causing autism. Rather, any conspiracy theory is presumed to be equally effective.
Yet, anecdotal observations suggest that, in situations that threaten control and undermine people's sense of order, it is conspiracy beliefs related to the specific control threat that are affected. For example, after high-profile terrorist attacks, such as those on the twin towers or the London underground, there is increased popularity not just in any conspiracy theory, but in those that attempt to explain the events at hand (e.g., that the U.S. government orchestrated 9/11, etc.). Similarly, in the wake of the COVID-19 pandemic, it is COVID-19 conspiracy theories that seem to have proliferated, not simply conspiracy theories in general. Google searches for "man made virus," but not for other popular conspiracy theories, peaked around the time it was clear COVID-19 was going to be a world-wide pandemic, while more recently, searches for "vaccine conspiracy" have begun to increase (see Fig. 1). Consistent with these observations, Stojanov et al. (2020) found that, in the wake of a series of devastating tornados in the United States, belief in weather-related conspiracy beliefs, but not in other conspiracy

Table 1 Matrix of correlation coefficients for the examined variables for the New Zealand sample

\begin{tabular}{|c|c|c|c|c|c|c|c|c|c|c|}
\hline & Cronbach Alpha & 1 & 2 & 3 & 4 & 5 & 6 & 7 & 8 & 9 \\
\hline Generic conspiracy beliefs & 0.83 & & & & & & & & & \\
\hline Specific conspiracy beliefs & 0.93 & $0.50^{* *}$ & & & & & & & & \\
\hline COVID-19 conspiracy beliefs & 0.94 & $0.47^{* *}$ & $0.66^{* *}$ & & & & & & & \\
\hline COVID-19 perceived control & 0.60 & -0.07 & -0.01 & 0.01 & & & & & & \\
\hline General control (state) & 0.64 & -0.12 & -0.08 & 0.00 & 0.10 & & & & & \\
\hline General control (trait) & 0.72 & $-0.24^{* *}$ & $-0.20^{*}$ & -0.09 & 0.05 & $0.66^{* *}$ & & & & \\
\hline Affectedness & 0.60 & 0.07 & 0.15 & $0.19^{*}$ & -0.13 & $-0.39^{* *}$ & $-0.25^{* *}$ & & & \\
\hline Government competence & 0.60 & -0.15 & -0.09 & -0.03 & 0.16 & 0.16 & $0.28^{* *}$ & 0.00 & & \\
\hline Arousal & - & $0.28^{* *}$ & $0.21^{*}$ & $0.18^{*}$ & 0.00 & -0.07 & -0.04 & 0.07 & -0.01 & \\
\hline Positivity & - & 0.08 & 0.09 & $0.24^{* *}$ & 0.09 & $0.19^{*}$ & 0.01 & -0.13 & -0.11 & 0.16 \\
\hline
\end{tabular}

$* * p<0.01, * p<0.05$ 
Table 2 Matrix of correlation coefficients for the examined variables for the Republic of North Macedonia (RNM) sample

\begin{tabular}{|c|c|c|c|c|c|c|c|c|c|c|}
\hline & Cronbach Alpha & 1 & 2 & 3 & 4 & 5 & 6 & 7 & 8 & 9 \\
\hline Generic conspiracy beliefs & 0.86 & & & & & & & & & \\
\hline Specific conspiracy beliefs & 0.92 & $0.67^{* *}$ & & & & & & & & \\
\hline COVID-19 conspiracy beliefs & 0.92 & $0.62^{* * *}$ & $0.69^{* *}$ & & & & & & & \\
\hline COVID-19 perceived control & 0.49 & $-0.21^{*}$ & -0.13 & $-0.24^{* *}$ & & & & & & \\
\hline General control (state) & 0.71 & $-0.20^{*}$ & $-0.22^{*}$ & -0.13 & $0.30^{* *}$ & & & & & \\
\hline General control (trait) & 0.76 & $-0.24^{* *}$ & $-0.21^{*}$ & -0.15 & $0.33^{* *}$ & $0.80^{* *}$ & & & & \\
\hline Affectedness & 0.74 & -0.05 & 0.04 & 0.04 & 0.01 & $-0.40^{* *}$ & $-0.23^{* *}$ & & & \\
\hline Government competence & 0.68 & $-0.29^{* *}$ & $-0.25^{* *}$ & $-0.18^{*}$ & 0.10 & -0.08 & -0.05 & $0.22^{*}$ & & \\
\hline Arousal & - & -0.14 & -0.17 & $-0.20^{*}$ & 0.05 & -0.05 & -0.04 & 0.10 & 0.13 & \\
\hline Positivity & - & 0.01 & 0.08 & 0.08 & $0.20^{*}$ & $0.32^{* *}$ & $0.24^{* * *}$ & $-0.45^{* *}$ & -0.07 & -0.09 \\
\hline
\end{tabular}

$* * p<0.01, * p<0.05$

beliefs, was significantly higher compared to three months after the tornadoes.

In sum, there is reason to believe that the presumed link between perceived lack of control and conspiracy beliefs may be more nuanced than previous investigators have allowed, involving domain-specific but not domain-general compensatory processes. We can thus refine our primary hypothesis to the prediction that COVID-19 control threat will predict belief only in COVID-19-related conspiracy beliefs, and only in the Macedonian group. We also posit that general control threat will not predict belief in any type of conspiracy theories. Finally, we hypothesize that the predicted effect will hold even when we control for potentially confounding variables such as the subjective impact of COVID-19, trait control, and current emotional state.

Table 3 Means and Standard deviations for the variables of interest

\begin{tabular}{lrrrrr}
\hline & \multicolumn{2}{l}{ RNM group } & & \multicolumn{2}{l}{ NZ group } \\
\cline { 2 - 3 } \cline { 7 - 7 } & M & SD & & M & SD \\
\hline Generic conspiracy beliefs & 4.43 & 1.09 & & 3.29 & 1.06 \\
Specific conspiracy beliefs & 4.57 & 1.69 & & 3.23 & 1.53 \\
COVID-19 conspiracy beliefs & 3.50 & 2.00 & & 2.07 & 1.55 \\
COVID-19 perceived control & 3.06 & 0.45 & & 2.91 & 0.50 \\
General control (state) & 2.80 & 0.42 & & 2.81 & 0.37 \\
General control (trait) & 2.84 & 0.44 & & 2.91 & 0.40 \\
Affectedness & 3.93 & 1.46 & & 3.45 & 0.97 \\
Government competence & 3.81 & 1.10 & & 5.53 & 0.85 \\
Arousal & -0.27 & 2.75 & & -0.41 & 2.59 \\
Positivity & -1.72 & 2.07 & -3.43 & 1.63 \\
\hline
\end{tabular}

\section{Method}

\section{Participants}

Participants were 253 undergraduate students. The Macedonian sample consisted of 122 undergraduate psychology students, all volunteers, enrolled at a Macedonian university ( 15 male, 107 female, $\left.M_{\text {age }}=20.31, S D_{\text {age }}=1.51\right)$. The New Zealand sample consisted of 131 undergraduate psychology students, enrolled at a New Zealand university (21 male, 110 female, $M_{\text {age }}=19.82, S D_{\text {age }}=2.70$ ). GPower (Faul et al., 2009) analysis with expected effect size $f=0.1$, alpha of 0.05 , power of $95 \%$ and 7 predictors indicated a required total sample size of 226 .

\section{Procedure and Instruments}

The survey was prepared originally in English; the Macedonian version was translated by the first author in consultation with the fourth author, both of whom are native speakers. The surveys were administered on-line via the Qualtrics platform in April and May 2020.

General Control Threat To measure control threat in general, we first administered the Mastery Scale (Pearlin \& Schooler,

Table 4 Means, Standard deviations, and t-test results for the differences in perceived government competence

\begin{tabular}{|c|c|c|c|c|c|c|c|}
\hline & \multicolumn{2}{|c|}{ RNM group } & \multicolumn{2}{|c|}{ NZ group } & \multirow[b]{2}{*}{$t(d f)$} & \multirow[b]{2}{*}{$p$} & \multirow[b]{2}{*}{$d$} \\
\hline & $M$ & $S D$ & $M$ & $S D$ & & & \\
\hline Medical crisis & 4.00 & 1.50 & 5.68 & 1.1 & $10.25(251)$ & $<0.01$ & 1.28 \\
\hline Economic crisis & 2.92 & 1.36 & 4.73 & 1.30 & $10.88(251)$ & $<0.01$ & 1.36 \\
\hline COVID-19 crisis & 4.51 & 1.37 & 6.18 & 1.01 & $11.04(251)$ & $<0.01$ & 1.39 \\
\hline
\end{tabular}


Table 5 Moderation model with COVID-19 conspiracy beliefs as DV and COVID-19-related control as independent variable
Model $1\left(R^{2}=0.23, \Delta R^{2}\right.$ (due to the interaction $\left.)=0.02\right)$

\begin{tabular}{lrrrrrr}
\hline & \multicolumn{1}{l}{$\mathrm{B}$} & $\mathrm{SE}$ & $\mathrm{t}$ & $\mathrm{p}$ & $\mathrm{LLCI}$ & $\mathrm{ULCI}$ \\
\hline Constant & 2.92 & 1.29 & 2.26 & 0.02 & 0.37 & 5.47 \\
COVID19-related control & 0.02 & 0.30 & 0.08 & 0.94 & -0.57 & 0.62 \\
Group & 4.55 & 1.41 & 3.22 & $<0.01$ & 1.77 & 7.34 \\
COVID19-related control * Group & -1.20 & 0.47 & -2.56 & 0.01 & -2.12 & -0.28 \\
Arousal & -0.03 & 0.04 & -0.84 & 0.40 & -0.11 & 0.05 \\
Positivity & 0.24 & 0.06 & 3.76 & $<0.01$ & 0.11 & 0.36 \\
Affectedness & 0.23 & 0.10 & 2.42 & 0.02 & 0.04 & 0.42 \\
General control (trait) & -0.32 & 0.27 & -1.17 & 0.24 & -0.85 & 0.22 \\
\hline
\end{tabular}

1978), which consists of seven items (e.g., "I have little control over the things that happen to me") meant to capture the extent to which people feel they have control over their life (Pearlin et al., 1981). Participants answered on a 4-point Likert-type scale ( 1 = strongly disagree, $4=$ strongly agree), with several items being reverse-coded, such that higher scores indicate greater perceived control. The scale was administered twice, once telling participants that "we are interested in how you look at some things in the last month or two" (measuring state perceived control) and once asking about "how you look at the same things in life in general" (measuring trait perceived control), always in that order.

Perceptions of specific control over COVID-19 were measured with four items (e.g., "Contracting Covid-19 is a matter of chance over which I have no influence", "Contracting Covid19 is a matter of my behavior", "It will be partly my fault if I get Covid-19”, "I feel totally helpless regarding COVID-19”). Participants again rated their agreement on a 4-point Likert-type scale ( $1=$ strongly disagree, $4=$ strongly agree). As with the previous scale, items were recoded so that higher scores indicated higher perceived control.

COVID-19 Related Conspiracy Beliefs We used eight items to measure COVID-19 related conspiracy beliefs ("COVID-19 is part of a Chinese biological weapons program"; "COVID-19 is a biological weapon manufactured by the CIA and the US is waging economic war on China using the virus"; "COVID-19 was manufactured to precipitate a global stock market collapse so that certain individuals/groups could profit"; "The outbreak of COVID-19 is a scheme to eliminate the sick and elderly"; "The COVID-19 outbreak is cover-up for a 5G-related illness"; "The outbreak of COVID-19 is a scheme where people's liberties are gradually taken"; "COVID-19 was released so that the pharmaceutical industry could profit from new medicine or a vaccine"; "COVID-19 is a scheme by several power sources aiming to establish a new world order"). Participants answered on a 9point scale $(1=$ completely false, $9=$ completely true $)$.

COVID-19 Unrelated Conspiracy Beliefs We used the Beliefs in Conspiracy Theories Inventory (BCTI, Swami et al., 2010; Swami et al., 2011), a 15-item scale that measures belief in specific conspiracy theories (e.g., "The Apollo moon landings never happened and were staged in a Hollywood film studio") to assess belief in COVID-19-unrelated conspiracy beliefs. Participants answer on a 9-point scale ( $1=$ completely false, $9=$ completely true).

General Tendency to Believe in Conspiracy Theories We used the conspiracy theory ideation subscale of the Conspiracy Mentality scale (Stojanov \& Halberstadt, 2019) to assess the
Table 6 Moderation model with specific (COVID-19 unrelated) conspiracy beliefs as DV and COVID-19-related control as independent variable

\begin{tabular}{|c|c|c|c|c|c|c|}
\hline & B & SE & $\mathrm{t}$ & $\mathrm{p}$ & LLCI & ULCI \\
\hline Constant & 5.39 & 1.19 & 4.52 & $<0.01$ & 3.05 & 7.74 \\
\hline COVID19-related control & -0.01 & 0.28 & -0.03 & 0.97 & -0.56 & 0.54 \\
\hline Group & 2.08 & 1.30 & 1.60 & 0.11 & -0.48 & 4.65 \\
\hline COVID19-related control * Group & -0.35 & 0.43 & -0.81 & 0.42 & -1.20 & 0.50 \\
\hline Arousal & 0.00 & 0.04 & -0.07 & 0.95 & -0.08 & 0.07 \\
\hline Positivity & 0.13 & 0.06 & 2.27 & 0.02 & 0.02 & 0.24 \\
\hline Affectedness & 0.12 & 0.09 & 1.32 & 0.19 & -0.06 & 0.29 \\
\hline General control (trait) & -0.72 & 0.25 & -2.88 & $<0.01$ & -1.21 & -0.23 \\
\hline
\end{tabular}


Fig. 2 The moderating effect of group on the relationship between COVID-19 related control and COVID-19 related conspiracy beliefs

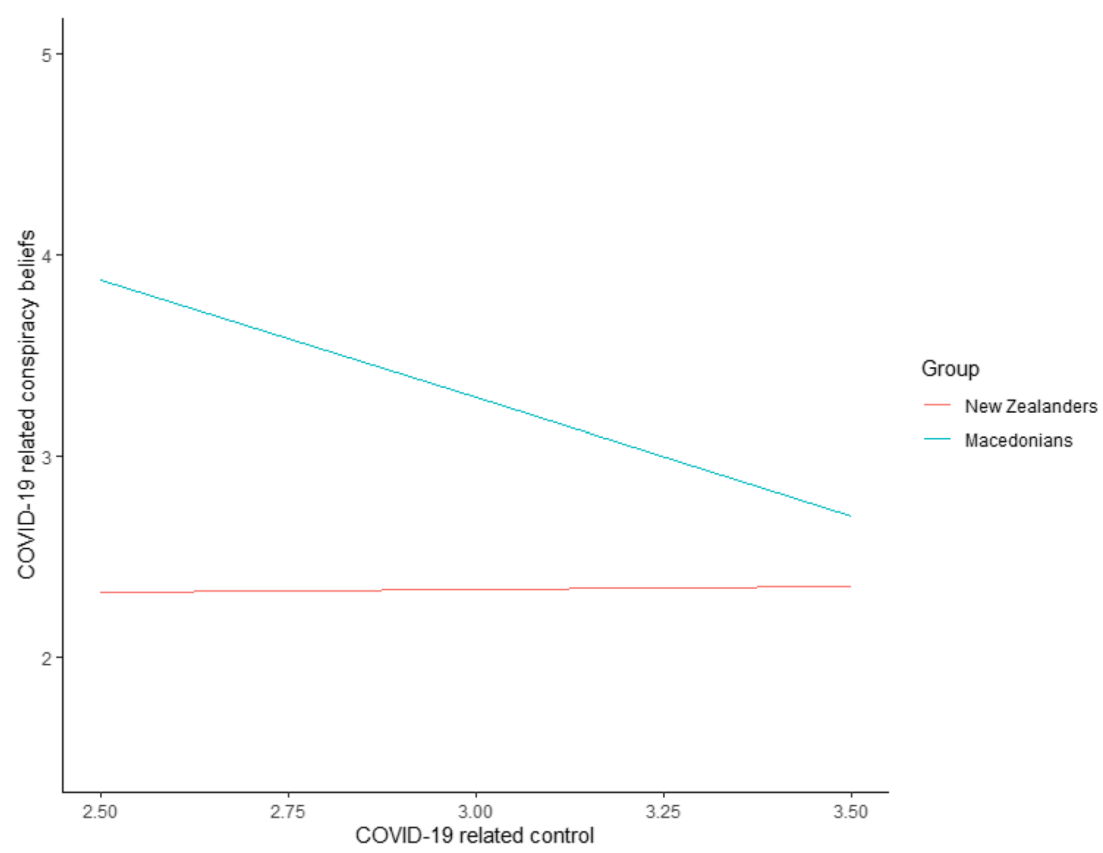

general tendency to believe in conspiracy theories. Participants rated their agreement with seven items (e.g., "Some things that everyone accepts as true are in fact hoaxes created by people in power") on a 7-point scale ( $1=$ strongly disagree, $7=$ strongly agree).

Affectedness by COVID-19 was measured with five items (e.g., "To what extent have you suffered physical harm as a result of the outbreak?", "To what extent have you suffered psychological harm as a result of the outbreak?", "To what extent do you feel your life is in danger because of Covid-19?", "To what extent is your daily routine affected by the outbreak?", "Overall to what extent has your life been affected by the outbreak?") adapted from Segal et al. (2018). Participants rated the items on a 9-point scale $(0=$ not at all, $8=$ very much so).

Arousal was measured by asking participants to "Please position the slider in a way that indicates how aroused you are when you think of COVID-19.", based on Betella and Verschure (2016). One end of the slider was anchored with a "sleepy" emoticon (-5) and the other with "wide awake" emoticon (+5). The initial position of the slider was set to 0 .

Positivity/Negativity was measured by asking participants to "Please position the slider in a way that indicates how much pleasure you feel when you think of COVID-19" (after Betella $\&$ Verschure, 2016). One end of the slider was anchored with a sad emoticon $(-5)$ and the other with happy emoticon $(+5)$. Again, the initial position of the slider was set to 0 .

\section{Results}

The matrix of correlations between the examined variables, for each subgroup separately are given in Tables 1 and 2 . The descriptive statistics for the variables, by group, are given in Table 3.

We first checked whether the government was indeed perceived as less competent in the Macedonian group, as we hypothesized. As can be seen in Table 4, the Macedonian ${ }^{1}$ participants perceived the government as less competent to manage the medical crisis and economic crisis caused by COVID-19 and the COVID-19 crisis in general.

Next, we tested for measurement invariance to establish that the measurements are comparable between groups. In particular, we were interested in metric equivalence (i.e. equivalence of the factor loadings) as we compared relationships between variables (Wang et al., 2018). To test for metric invariance, the regression weights are constrained to be equal across the groups and model fit is estimated. The constrained model fit indices are compared with the ones from the configural model. A significant $\Delta \chi^{2}$ indicates nonequivalence, as well as $\triangle$ CFI greater than 0.01 (Cheung \& Rensvold, 2002), $\triangle$ RMSEA values greater than 0.015 (Chen, 2007) and $\triangle$ SRMR values greater than 0.03 (Chen, 2007).

As can be seen from Table 1 in the supplementary materials, all measured variables met the requirement for full or partial invariance (Putnick \& Bornstein, 2016) - unit change in the Macedonian group was equivalent to unit change in the New Zealand group - meaning we could meaningfully proceed with the main analysis.

To test our hypotheses that COVID-19 control threat would predict belief only in COVID-19-related conspiracy beliefs, and only in the Macedonian group, while general control

\footnotetext{
${ }^{1}$ For simplicity, the participants from the Republic of North Macedonia are referred to as Macedonian participants.
} 
Table 7 Moderation model with generic conspiracy beliefs as DV and COVID-19 related control as independent variable

\begin{tabular}{|c|c|c|c|c|c|c|}
\hline & $\mathrm{B}$ & SE & $\mathrm{t}$ & $\mathrm{p}$ & LLCI & ULCI \\
\hline Constant & 5.74 & 0.79 & 7.24 & $<0.01$ & 4.18 & 7.31 \\
\hline COVID19-related control & -0.15 & 0.189 & -0.82 & 0.41 & -0.52 & 0.21 \\
\hline Group & 1.70 & 0.87 & 1.96 & 0.05 & -0.01 & 3.41 \\
\hline COVID19-related control * Group & -0.21 & 0.29 & -0.74 & 0.46 & -0.78 & 0.35 \\
\hline Arousal & 0.03 & 0.02 & 1.05 & 0.29 & -0.02 & 0.08 \\
\hline Positivity & 0.05 & 0.04 & 1.24 & 0.22 & -0.03 & 0.12 \\
\hline Affectedness & -0.03 & 0.06 & -0.57 & 0.57 & -0.15 & 0.08 \\
\hline General control (trait) & -0.59 & 0.17 & -3.56 & $<0.01$ & -0.92 & -0.26 \\
\hline
\end{tabular}

threat would not predict belief in any type of conspiracy beliefs, we ran six moderation models (Model 1 in PROCESS, (Hayes, 2013)), with nationality always as a moderator variable, and the independent variable operationalized as either COVID-19 related control or general control (state), and the dependent variable operationalized as either COVID-19 related conspiracy beliefs, specific (COVID-19 non related) conspiracy beliefs, or generic conspiracy beliefs. Affectedness, arousal, positivity, and general control (trait) were always entered as covariates. The first model tested the effects of COVID-19 control threat on COVID-19-related conspiracy beliefs as a function of group. The results are presented in Table 5 and Fig. 2. As expected, there was significant interaction $(B=-1.20, S E=0.47,95 \% C I[-2.12,-0.28])$ between group and COVID-19 related control, such that the less COVID-19 control the Macedonian participants reported, the more they believed in COVID-19-related conspiracy theories $(B=-1.17, S E=0.36,95 \% C I[-1.88,-0.47])$, but there was no relationship between these two variables for the New Zealand sample $(B=0.02, S E=0.30,95 \% C I[-0.57,0.62])$. There was neither a main effect of control (operationalized as either COVID-19-related or general) nor an interaction for any of the other five models (see Tables 6, 7, 8, 9 and 10). However, in four out of six models there was a main effect of group, such that Macedonian participants scored higher on the conspiracy belief measures compared to their New Zealand counterparts.

To test further for domain specificity, we analyzed separately each item of the BCTI, with the item as DV, COVID-19 related control as IV and nationality as moderator. As can be seen from Table 2 in the supplementary materials, the interaction between item and group was significant in the case of only one item ("SARS (Severe Acute Respiratory Syndrome) was produced under laboratory conditions as a biological weapon"), whose subject is most closely related to that of COVID-19, B $=-1.27 \mathrm{SE}=0.57,95 \%$ CI $[-2.39$, $-0.16]$.

\section{Discussion and Conclusion}

Academic interest in the psychological underpinnings of conspiracy theory belief has increased dramatically over the past decade (Douglas et al., 2019a, b), with most work in this area suggesting that conspiracy beliefs are due, at least in part, to motivational factors involving a lack of control (Douglas et al., 2017). The prevailing theoretical framework used to explain conspiracy theory beliefs has been compensatory
Table 8 Moderation model with COVID-19 conspiracy beliefs as DV and general control as independent variable

\begin{tabular}{lrrrrrr}
\hline Model $4\left(R^{2}=0.21, \Delta R^{2}=0.00\right)$ & & & & & & \\
& $\mathrm{B}$ & $\mathrm{SE}$ & $\mathrm{t}$ & $\mathrm{p}$ & LLCI & ULCI \\
\hline Constant & 2.48 & 1.37 & 1.81 & 0.07 & -0.22 & 5.18 \\
Current General control & 0.46 & 0.52 & 0.90 & 0.37 & -0.56 & 1.49 \\
Group & 2.75 & 1.60 & 1.72 & 0.09 & -0.41 & 5.90 \\
Current General control * Group & -0.64 & 0.56 & -1.14 & 0.25 & -1.76 & 0.47 \\
Arousal & -0.04 & 0.04 & -0.92 & 0.36 & -0.12 & 0.04 \\
Positivity & 0.21 & 0.06 & 3.22 & $<0.01$ & 0.08 & 0.33 \\
Affectedness & 0.20 & 0.10 & 1.99 & 0.05 & 0.00 & 0.40 \\
General control (trait) & -0.59 & 0.39 & -1.52 & 0.13 & -1.35 & 0.17 \\
\hline
\end{tabular}


Table 9 Moderation model with specific (COVID-19 unrelated) conspiracy beliefs as DV and general control as independent variable

\begin{tabular}{|c|c|c|c|c|c|c|}
\hline & $\mathrm{B}$ & SE & $\mathrm{t}$ & $\mathrm{p}$ & LLCI & ULCI \\
\hline Constant & 4.88 & 1.24 & 3.94 & $<0.01$ & 2.44 & 7.33 \\
\hline Current General control & 0.16 & 0.47 & 0.34 & 0.73 & -0.76 & 1.08 \\
\hline Group & 2.56 & 1.45 & 1.77 & 0.08 & -0.29 & 5.41 \\
\hline Current General control * Group & -0.54 & 0.51 & -1.07 & 0.29 & -1.55 & 0.46 \\
\hline Arousal & 0.00 & 0.04 & -0.10 & 0.92 & -0.08 & 0.07 \\
\hline Positivity & 0.13 & 0.06 & 2.22 & 0.03 & 0.01 & 0.24 \\
\hline Affectedness & 0.10 & 0.09 & 1.04 & 0.30 & -0.08 & 0.28 \\
\hline General control (trait) & -0.69 & 0.35 & -1.96 & 0.05 & -1.38 & 0.00 \\
\hline
\end{tabular}

control theory, which proposes that people subscribe to conspiracy theories in an attempt to compensate for their perceived lack of control. However, findings in support of this model have been mixed, with some studies showing a causal link (Prooijen \& Acker, 2015), and other not (Stojanov \& Halberstadt, 2020).

In the current article, we posited-and subsequently tested - a more refined compensatory control hypothesis. Specifically, we postulated that threats to perceived control cause an increase in conspiracy theory beliefs only within the threatened domain, and only when other, less stigmatized, sources of compensatory control, such as central government, are unavailable.

The results supported our hypothesis. Powerlessness regarding COVID-19 predicted beliefs in COVID-19-related conspiracy theories, but not in unrelated ones. Furthermore, this was true only for the Macedonian participants, who, unlike New Zealand participants, perceived their government to be coping ineffectively with the crisis caused by COVID-19.

This is the first empirical study of which we are aware to show a domain-specific relationship between lack of control and conspiracy theory beliefs. These findings indicate that the lack of control in a particular domain may threaten perceptions of order in that domain, and suggest that compensatory efforts (Kay et al., 2008; Laurin et al., 2008) to restore perceptions of control and order may be more effective in that same domain. In other words, when it comes to the psychological factors driving conspiracy theory beliefs, compensatory control may not be as generalizable a process as has been assumed (for a review, see Stojanov et al., 2020), but may instead be localized to the source of the control loss.

If so, the present findings could help to account for the otherwise puzzling fact that previous experimental studies have found no clear causative link between personal control and conspiracy theory beliefs (Stojanov \& Halberstadt, 2020). If a domain-specific version of compensatory control theory is correct, then it is unsurprising that most of the existing work in this area, which has relied heavily on general control threats and sought to measure generic conspiracy theory endorsement, would be inconclusive.

That said, the current study is certainly not definitive with regard to the importance or explanatory scope of domainspecificity. Future studies should consider more precisely what constitutes a "domain," and the possibility that even within the same domain, some conspiracy claims will afford greater control than others. For example, the claim that COVID-19 virus "escaped" a lab may not offer as much compensatory control for its adherents as the claim that it was deliberately created for profit, as the former implies a more chaotic and random world than the latter.
Table 10 Moderation model with generic conspiracy beliefs as DV and general control as independent variable

\begin{tabular}{lrrrrrr}
\hline Model $6\left(R^{2}=0.27, \Delta R^{2}=0.00\right)$ & & & & & & \\
& $\mathrm{B}$ & $\mathrm{SE}$ & $\mathrm{t}$ & $\mathrm{p}$ & $\mathrm{LLCI}$ & ULCI \\
\hline Constant & 5.33 & 0.83 & 6.42 & $<0.01$ & 3.69 & 6.96 \\
Current General control & 0.03 & 0.31 & 0.11 & 0.92 & -0.59 & 0.65 \\
Group & 1.43 & 0.97 & 1.47 & 0.14 & -0.48 & 3.34 \\
Current General control * Group & -0.14 & 0.34 & -0.40 & 0.69 & -0.81 & 0.54 \\
Arousal & 0.02 & 0.03 & 0.99 & 0.33 & -0.02 & 0.07 \\
Positivity & 0.04 & 0.04 & 1.00 & 0.32 & -0.04 & 0.11 \\
Affectedness & -0.04 & 0.06 & -0.73 & 0.47 & -0.17 & 0.08 \\
General control (trait) & -0.63 & 0.23 & -2.69 & 0.01 & -1.09 & -0.17 \\
\hline
\end{tabular}


Moreover, an obvious limitation of the current study is its effectively correlational design. We cannot be certain that perceived lack of control regarding COVID-19 caused COVID-19 conspiracy beliefs; for example, COVID-19 could also have served as a salient reminder of death, and the effects driven by death-related anxiety (Newheiser et al., 2011). Furthermore, although we demonstrated that Macedonian participants perceived their government to be less competent compared to New Zealanders, and although we controlled for a number of co-variates, the two groups naturally differ on other variables as well that could explain the observed effects rather than, or in addition to, government competence. For example, North Macedonia has a higher index of "uncertainty avoidance" ("Country Comparison - Hofstede Insights", n.d. Kenig, 2006) - the degree to which people feel threatened by unknown and ambiguous situations - so belief in conspiracies could also represent an attempt to resolve the threat of the unknown. Our study was also limited to one context; the hypothesized domain-specific relationship between perceived control and conspiracy beliefs requires not only conceptual and direct replication in the context of COVID-19, but also replication in other domains in which control is theoretically compromised.

Despite these limitations, this is the first study to test, and find evidence for, a domain specific link in the compensatory control processes. Moreover, these results promise to revive the interest in the relationship between perceived control and conspiracy beliefs and direct the question from "whether" to "when" lack of control leads to conspiracy beliefs.

Supplementary Information The online version contains supplementary material available at https://doi.org/10.1007/s12144-021-01977-0.

Availability of Data and Material Data is available from the first authors upon request.

\section{Code Availability (Software Application or Custom Code) N/A}

\section{Declarations}

Ethics Approval Approval was obtained from the ethics committee of the University of Otago. The procedures used in this study adhere to the tenets of the Declaration of Helsinki.

Consent to Participate Informed consent was obtained from all individual participants included in the study.

Conflicts of Interest/Competing Interests The authors declare no conflict of interests.

\section{References}

Betella, A., \& Verschure, P. F. (2016). The affective slider: A digital selfassessment scale for the measurement of human emotions. PLoS One, 11(2), e0148037. https://doi.org/10.1371/journal.pone. 0148037.
Boden, M. T., Berenbaum, H., \& Gross, J. J. (2016). Why do people believe what they do? A functionalist perspective. Review of General Psychology, 20(4), 399-411. https://doi.org/10.1037/ gpr0000085.

Chang, R. \& Hong, J. (2020). Inside Bloomberg's Covid Resilience Ranking. https://www.bloomberg.com/news/articles/2020-11-24/ inside-bloomberg-s-covid-resilience-ranking. Accessed June 2021.

Chang, R., Hong, J. \& Varley, K. (2020). The best and worst places to be in Covid: U.S. Sinks in Ranking. https://www.bloomberg.com/ graphics/covid-resilience-ranking/. Accessed June 2021.

Chen, F. F. (2007). Sensitivity of goodness of fit indexes to lack of measurement invariance. Structural Equation Modeling, 14, 464504.

Cheung, G. W., \& Rensvold, R. B. (2002). Evaluating goodness-of-fit indexes for testing measurement invariance. Structural Equation Modeling, 9, 233-255.

Country Comparison - Hofstede Insights. (n.d.). Retrieved from https:// www.hofstede-insights.com/country-comparison/newzealand,north-macedonia/. Accessed 7 Apr 2021.

Cummins, R. (1975). Functional analysis. The Journal of Philosophy, 72, 741-764. https://doi.org/10.2307/2024640.

Douglas, K. M., Sutton, R. M., \& Cichocka, A. (2017). The psychology of conspiracy theories. Current Directions in Psychological Science, 26(6), 538-542. https://doi.org/10.1177/0963721417718261.

Douglas, K. M., Sutton, R. M., \& Cichocka, A. (2019a). Belief in conspiracy theories: Looking beyond gullibility. In J. Forgas \& R. Baumeister (Eds.), The social psychology of gullibility: Conspiracy theories, fake news and irrational beliefs (pp. 61-76). Routledge. https://doi.org/10.4324/9780429203787.

Douglas, K. M., Uscinski, J., Sutton, R. M., Cichocka, A., Nefes, T., Ang, J., \& Deravi, F. (2019b). Understanding conspiracy theories. Advances in Political Psychology, 40(S1), 3-35.

Faul, F., Erdfelder, E., Buchner, A., \& Lang, A.-G. (2009). Statistical power analyses using $\mathrm{G}^{*}$ power 3.1: Tests for correlation and regression analyses. Behavior Research Methods, 41, 1149-1160.

Greenaway, K. H., Louis, W. R., \& Hornsey, M. J. (2013). Loss of control increases belief in precognition and belief in precognition increases control. PLoS One, 8(8), Article e71327. https://doi.org/ 10.1371/journal.pone.0071327.

Hayes, A. F. (2013). Introduction to mediation, moderation, and conditional process analysis: A regression-based approach. Guilford Press.

Kay, A. C., \& Eibach, R. P. (2013). Compensatory control and its implications for ideological extremism. Journal of Social Issues, 69(3), 564-585. https://doi.org/10.1111/josi.12029.

Kay, A. C., \& Sullivan, D. (2013). Cultural unity and diversity in compensatory control processes. In M. J. Gelfand, C. Chiu, \& a.; Y. Hong (Eds.), Advances in culture and psychology, Vol. 3 (pp. 181-226). Oxford University Press.

Kay, A. C., Gaucher, D., Napier, J. L., Callan, M. J., \& Laurin, K. (2008). God and the government: Testing a compensatory control mechanism for the support of external systems. Journal of Personality and Social Psychology, 95, 18-35. https://doi.org/10.1037/0022-3514. 95.1.18.

Kay, A. C., Shepherd, S., Blatz, C. W., Chua, S. N., \& Galinsky, A. D. (2010). For god (or) country: The hydraulic relation between government instability and belief in religious sources of control. Journal of Personality and Social Psychology, 99(5), 725-739.

Kay, A. C., Sullivan, D., \& Landau, M. J. (2015). Psychological importance of beliefs in control and order: Historical and contemporary perspectives in social and personality psychology. In M. Mikulincer, P. R. Shaver, E. Borgida, \& J. A. Bargh (Eds.), APA handbooks in psychology. APA handbook of personality and social psychology, Vol. 1. Attitudes and social cognition (pp. 309-337). American Psychological Association. https://doi.org/10.1037/14341-010. 
Kenig, N. (2006). Hofstede's Model of Cultural Dimensions: Possibilities for Measurement in Group and Individual Context [Unpublished doctoral dissertation]. Ss. "Cyril and Methodius University" Skopje.

Lantian, A., Muller, D., Nurra, C., Klein, O., Berjot, S., \& Pantazi, M. (2018). Stigmatized beliefs: Conspiracy theories, anticipated negative evaluation of the self, and fear of social exclusion. European Journal of Social Psychology, 48, 939-954. https://doi.org/10.1002/ ejsp.2498.

Laurin, K., Kay, A. C., \& Moscovitch, D. A. (2008). On the belief in god : Towards an understanding of the emotional substrates of compensatory control. Journal of Experimental Social Psychology, 44, 1559-1562. https://doi.org/10.1016/j.jesp.2008.07.007.

Lerner. M. J. (1980). The belief in a just world: a fundamental delusion. Plenum Press.

Newheiser, A.-K., Farias, M., \& Tausch, N. (2011). The functional nature of conspiracy beliefs: Examining the underpinnings of belief in the Da Vinci Code conspiracy. Personality and Individual Differences, 51(8), 1007-1011.

Norenzayan, A., \& Hansen, I. G. (2006). Belief in supernatural agents in the face of death. Personality and Social Psychology Bulletin, 32, 174-187. https://doi.org/10.1177/0146167205280251.

Pearlin, L. I., \& Schooler, C. (1978). The structure of coping. Journal of Health and Social Behavior, 19(1), 2-21. https://doi.org/10.2307/ 2136319.

Pearlin, L. I., Menaghan, E. G., Lieberman, M. A., \& Mullan, J. T. (1981). The stress process. Journal of Health and Social Behavior, 22, 337-356. https://doi.org/10.2307/2136676.

Prooijen, J.-W., \& Acker, M. (2015). The influence of control on belief in conspiracy theories: Conceptual and applied extensions. Applied Cognitive Psychology, 29(5), 753-761. https://doi.org/10.1002/ acp. 3161 .

Putnick, D. L., \& Bornstein, M. H. (2016). Measurement invariance conventions and reporting: The state of the art and future directions for psychological research. Developmental Review, 41, 71-90. https://doi.org/10.1016/j.dr.2016.06.004.

Rutjens, B. T., van Harreveld, van der Pligt, J., Kreemers, L. M., \& Noordewier, M. K. (2013). Steps, stages, and structure : Finding compensatory order in scientific theories. Journal of Experimental Social Psychology, 142, 313-318. https://doi.org/10.1037/ a0028716.

Segal, K., Jong, J., \& Halberstadt, J. (2018). The fusing power of natural disasters: An experimental study. Self and Identity, 17, 574-586.
Stojanov, A., \& Halberstadt, J. (2019). The conspiracy mentality scale: Distinguishing between irrational and rational suspicion. Social Psychology, 50(4), 215-232. https://doi.org/10.1027/1864-9335/ a000381.

Stojanov, A., \& Halberstadt, J. (2020). Does lack of control lead to conspiracy beliefs? A meta-analysis. European Journal of Social Psychology, 50, 955-968. https://doi.org/10.1002/ejsp.2690.

Stojanov, A., Bering, J. M., \& Halberstadt, J. (2020). Does perceived lack of control lead to conspiracy theory beliefs? Findings from an online MTurk sample. PLoS One, 15(8), e0237771. https://doi.org/10. 1371/journal.pone.0237771.

Swami, V., Chamorro-Premuzic, T., \& Furnham, A. (2010). Unanswered questions: A preliminary investigation of personality and individual difference predictors of 9/11 conspiracist beliefs. Applied Cognitive Psychology, 24, 749-761.

Swami, V., Coles, R., Stieger, S., Pietschnig, J., Furnham, A., Rehim, S., \& Voracek, M. (2011). Conspiracist ideation in Britain and Austria: Evidence of a monological belief system and associations between individual psychological differences and real-world and fictitious conspiracy theories. British Journal of Psychology, 102(3), 443463. https://doi.org/10.1111/j.2044-8295.2010.02004.x.

Transparency International. (n.d.) https://www.transparency.org/en/cpi/ 2018/results/mkd. Accessed June 2021.

van Elk, M., \& Lodder, P. (2018). Experimental manipulations of personal control do not increase illusory pattern perception. Collabra, $4,1-22$.

Wang, S., Chen, C.-C., Dai, C.-L., \& Richardson, G. B. (2018). A call for, and beginner's guide to, measurement invariance testing in evolutionary psychology. Evolutionary Psychological Science, 4(2), 166178. https://doi.org/10.1007/s40806-017-0125-5.

Whitson, J. A., \& Galinsky, A. D. (2008). Lacking control increases illusory pattern perception. Science, 322(5898), 115-117. https:// doi.org/10.1126/science.1159845.

Wright, L. (1973). Functions. The Philosophical Review, 82, 139-168. https://doi.org/10.2307/2183766.

Евросимоски, Д. (2020). https://www.radiomof.mk/infografik-kako-smakedonija-se-spravuva-so-kovid-19-vo-sporedba-so-regionot/. Accessed June 2021.

Publisher's Note Springer Nature remains neutral with regard to jurisdictional claims in published maps and institutional affiliations. 